\title{
O algoritmo da multiplicação: possibilidades de diferentes formas de matematizar
}

Juliana Batista Pereira dos Santos

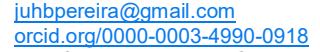

Pontifícia Universidade Católica do Rio Grande do Sul (PUCRS), Porto Alegre, Rio Grande do Sul, Brasil

Isabel Cristina Machado de Lara isabel.lara@pucrs.br

orcid.org/0000-0002-0574-8590

Po Rio Grande do Sul (PUCRS), Porto Alegre, Rio Grande do Sul, Brasil

\section{RESUMO}

Este artigo tem como objetivo investigar quais os efeitos imediatos da articulação entre a História da Matemática e a Etnomatemática na realização de uma proposta de ensino, voltada a estudantes do $5^{\circ}$ ano do Ensino Fundamental. A proposta foi realizada com dezoito estudantes de uma escola pública da cidade de Porto Alegre, RS, e abordou o ensino da multiplicação. Os dados foram obtidos a partir de um questionário, com nove questões de respostas abertas, aplicado aos estudantes após realização da proposta. Para analisar os resultados obtidos utilizou-se como método a análise genealógica discursiva, adotando-se como ferramentas analíticas os escritos de Michel Foucault, em especial sobre os conceitos de poder e saber, e de Ludwig Wittgenstein, sobre jogos de linguagem e semelhanças de família. Evidencia-se que, por meio da proposta de ensino, os estudantes: sentiram-se motivados a aprender outras formas para a realização do produto; conheceram outros modos de matematizar; reforçaram sua aprendizagem sobre o algoritmo da multiplicação em seus jogos de linguagem escolares. Além disso, mostra-se que as atividades realizadas ao longo da proposta de ensino possibilitaram aos estudantes: conhecer outras formas de matematizar, através de jogos de linguagens com suas regras específicas; rever aspectos relativos ao algoritmo da multiplicação ensinado nas escolas; além de refletir acerca das vantagens que outros jogos de linguagem têm sobre o jogo de linguagem da Matemática Escolar e vice-versa.

PALAVRAS-CHAVE: História da Matemática. Etnomatemática. Anos iniciais. Ensino Fundamental. Multiplicação. 


\section{INTRODUÇÃO}

A História da Matemática e a Etnomatemática são duas, entre outras, tendências do campo da Educação Matemática. Porém, apresentam caminhos de pesquisas, problemas de investigação e referenciais teóricos distintos e, na maior parte das vezes, independentes. A História da Matemática é a tendência que estuda "[...] fatos, datas e nomes associados à geração, à organização intelectual e social e à difusão do conhecimento - no nosso caso conhecimento matemático através das várias culturas ao longo da evolução da humanidade." (D'AMBROSIO, 2000, p. 241). A Etnomatemática analisa os "[...] modos, estilos, artes, técnicas, de explicar, aprender, conhecer, lidar com o ambiente natural, social, cultural e imaginário." (D'AMBROSIO, 2007, p. 2).

Entre as diversas possibilidades de pesquisas realizadas em ambas tendências, neste artigo considera-se apenas às relacionadas aos processos de ensino e de aprendizagem da Matemática nos anos iniciais do Ensino Fundamental. O mapeamento teórico realizado por Omena (2015) sobre História da Matemática, e o mapeamento teórico de Santos, Lara, Lima e Ferreira (2017) sobre Etnomatemática, apresentam um panorama sobre tais pesquisas.

Omena (2015) identificou 21 dissertações e teses que utilizaram a História da Matemática para elaborar propostas didáticas voltadas à Educação Básica. Dessas produções, sete são direcionadas aos anos finais do Ensino Fundamental, sendo uma para $\circ 7^{\circ}$ ano e seis para o $9^{\circ}$ ano. Das 14 produções voltadas ao Ensino Médio, a pesquisadora identificou cinco para o $1^{\circ}$ ano, duas para o $2^{\circ}$ ano, quatro para o $3^{\circ}$ ano e outras três não definidas pela pesquisadora.

Santos et al. (2017) encontraram 12 dissertações e teses que abordaram a Etnomatemática para a elaboração de propostas didáticas para o ensino de Matemática na Educação Básica. Dessas, cinco são voltadas ao Ensino Fundamental, sendo uma para os anos iniciais do Ensino Fundamental, duas para o $6^{\circ}$ ano, uma para o $7^{\circ}$ ano e uma voltada para toda a segunda etapa do Ensino Fundamental ( $6^{\circ}$ ao $9^{\circ}$ ano). Das sete produções restantes, uma não foi definida pelas pesquisadoras, três destinam-se a Educação de Jovens e Adultos (EJA), uma para o $1^{\circ}$ ano e duas para o $2^{\circ}$ ano, essas últimas do Ensino Médio.

A partir dos dois mapeamentos pode-se afirmar que as pesquisas, tanto em Etnomatemática como em História da Matemática, são escassas no que diz respeito aos anos iniciais do Ensino Fundamental. Entretanto, é durante esses primeiros anos escolares que se desenvolve a base para o entendimento de conceitos e estruturas matemáticas necessárias para os anos seguintes. Nesse sentido, emergem indagações como: é possível articular tais tendências nos processos de ensino e de aprendizagem de Matemática nos primeiros anos do Ensino Fundamental?; por que tais tendências não são frequentemente utilizadas nessa etapa de ensino?; os docentes conhecem e são preparados para utilizar tais tendências?; entre outras.

Para além dessas indagações, a questão que se torna latente e conduz este estudo é: Como a articulação dessas tendências na elaboração de propostas didáticas voltadas aos anos iniciais do Ensino Fundamental, contribui para os processos de ensino e de aprendizagem de Matemática? Para tanto foi elaborada uma proposta para o ensino da multiplicação desenvolvida com 18 estudantes do 50 ano do Ensino Fundamental, de uma escola pública da cidade de Porto Alegre, 
RS. A partir dos dados coletados da execução dessa proposta, pretende-se investigar quais os efeitos imediatos da articulação entre a História da Matemática e a Etnomatemática na realização de uma proposta de ensino, voltada à estudantes do $5^{\circ}$ ano do Ensino Fundamental. As análises foram fundamentadas nos estudos pós-estruturalistas de Michel Foucault, em especial nos conceitos de poder e saber, e em Ludwig Wittgenstein, sobre jogos de linguagem e semelhanças de família.

\section{REFERENCIAIS TEÓRICOS}

Dentre as variadas perspectivas teóricas relativas à Etnomatemática, adotase para esse estudo aquela que cria condições que possibilitam sua articulação com a História da Matemática. Nesse sentido, vale-se da perspectiva d'ambrosiana de Programa Etnomatemática cujo objetivo é "[...] procurar entender o saber/fazer matemático ao longo da história da espécie humana, contextualizado em diferentes grupos de interesse, comunidades, povos e nações." (D'AMBROSIO, 2007, p. 17). A Etnomatemática, nessa perspectiva, é um "[...] programa de pesquisa sobre geração, organização intelectual, organização social e difusão do conhecimento." (D’AMBROSIO, 1998, p. 26).

Desse modo, tratando-se especificamente do conhecimento matemático, é a História da Matemática que possibilita à Etnomatemática compreender a geração, organização e difusão do conhecimento matemático. Entretanto, para que a história possibilite compreender o saber/fazer ao longo dos processos de geração, organização e difusão do conhecimento matemático, é preciso deixar de considerá-la como um "[...] repositório fixo e invariável de objetos, técnicas, métodos, problemas, obstáculos, mecanismos de passagem [...] a ser total ou parcialmente transposto de uma forma mecânica para o plano de ensinoaprendizagem[...]" (MIGUEL; MIORIM, 2017, p. 177).

Miguel e Miorim (2017) argumentam que é preciso ir além da concepção de História como um repositório e aprofundar as reflexões no sentido de que a História é "[...] um conjunto heterogêneo de formas simbólicas produzidas por comunidades de memória envolvidas com diferentes prática sociais e produtoras de diferentes jogos de linguagem[...]" (MIGUEL; MIORIM, 2017, p. 177). Roque (2014) propõe definir o que é a História da Matemática partir da reflexão do que é a própria Matemática, pois, segundo a pesquisadora, perspectivas recentes relacionadas à História da Matemática defendem que a Matemática não se desenvolveu de modo linear e contínuo. Nas palavras da autora, "[...] não há uma matemática, que evolui linearmente ao longo do tempo, mas várias práticas matemáticas que nem sempre podem ser traduzidas umas nas outras." (ROQUE, 2014, p. 167, grifos da autora).

Tais práticas e formas simbólicas podem ser associadas ao que D'Ambrosio denomina modos de matematizar, ou seja, às diversas técnicas, modos e meios de explicar, conhecer e lidar com o ambiente a nossa volta. Esses modos de matematizar estão relacionados aos contextos nos quais se originam e se desenvolvem, visto que, o prefixo etno em Etnomatemática, representa um conceito amplo, que inclui grupos que partilham de símbolos, códigos e mitos, Acadêmica ${ }^{1}$ (D'AMBROSIO, 1998). 
Segundo Vilela (2016), a dinamicidade do Programa Etnomatemática é consoante com a filosofia de Wittgenstein, visto que não é prescritiva, ou seja, ambos os autores não propõem definições fechadas e estanques aos seus conceitos. Além disso, outras semelhanças entre as teorizações dos dois pensadores podem ser estabelecidas, destacando as aproximações entre as noções d'ambrosianas de etno e modos de matematizar, com os conceitos wittgensteinianos de formas de vida e jogos de linguagem, respectivamente.

Para o filósofo, o jogo de linguagem é "[...] o conjunto da linguagem e das atividades com as quais está interligada." (WITTGENSTEIN, 1979, p. 12), de modo que, o significado de uma palavra na linguagem se dá pelo uso que dela se faz. Assim, se reconduz "[...] as palavras de seu emprego metafísico para seu emprego cotidiano." (WITTGENSTEIN, 1979, p. 55). Nesse sentido, a linguagem é contingente, pois, "[...] novos tipos de linguagem, novos jogos de linguagem, como poderíamos dizer, nascem e outros envelhecem e são esquecidos." (WITTGENSTEIN, 1979, p. 18).

Apesar de cada forma de vida apresentar jogos de linguagem próprios, o filósofo reconhece a existência de semelhanças entre os múltiplos jogos: "Pois, se você os contempla, não verá na verdade algo que fosse comum a todos, mas verá semelhanças, parentescos, e até toda uma série deles." (WITTGENSTEIN, 1979, p. 38). A essas semelhanças existentes entre determinados jogos de linguagem, Wittgenstein chamou de semelhanças de família: "E por causa desse parentesco ou desses parentescos, chamamo-los todos de "linguagens"." (WITTGENSTEIN, 1979, p. 38).

O novo olhar para a linguagem e a significação, trazido por Wittgenstein, evidencia a relação de dependência entre os jogos de linguagem e o contexto no qual ocorre, emergindo assim o conceito de formas de vida. Para o filósofo, a forma de vida é definida menos por questões biológicas e mais por questões culturais, pois "[...] representar uma linguagem significa representar-se uma forma de vida." (WITTGENSTEIN, 1979, p. 15). Diante dessa relação entre significação e uso, Wittgenstein defende que se é na práxis que se estabelece o uso da linguagem, dessa forma não há uma linguagem, mas um conjunto de linguagens que variam de acordo com o emprego atribuído à palavra.

Como destaca D'Ambrosio (2007), diferentes grupos culturais produzem diferentes modos de matematizar, ou ainda, o saber/fazer matemático relacionase ao contexto natural e social em que é produzido. De forma semelhante, Wittgenstein (1979), em sua filosofia de maturidade ${ }^{2}$, defende que cada forma de vida tem seus próprios jogos de linguagem. Estabelecendo um comparativo com D'Ambrosio, equivale dizer que cada grupo social, étnico, laboral ou cultural tem sua própria forma de vida, ou mais do que isso, é uma forma de vida no sentido wittgensteiniano do termo, ou seja, partilham da mesma cultura e possuem seus próprios hábitos, códigos e signos.

A confluência desses dois autores possibilita a emergência de, pelo menos, duas reflexões: se durante o desenvolvimento dos conceitos matemáticos próprios da Matemática Acadêmica diversos modos de matematizar, ou em termos wittgensteinianos, diversos jogos de linguagem, foram mobilizados, por que apenas alguns desses jogos se tornaram hegemônicos?; por qual motivo o ensino da Matemática prioriza um único modo de matematizar, marginalizando os demais? 
É por meio da História que se cria condições que possibilitam trazer à tona as relações de poder que constituíram a hegemonia de determinados jogos de linguagem e não outros, organizando-os e difundindo-os. Segundo Foucault (1999, p. 31), "[...] não há relação de poder sem constituição correlata de um campo de saber, nem saber que não suponha e não constitua ao mesmo tempo relações de poder.".

O poder, para Foucault, não pertence a alguém ou a uma instituição: “Nunca está localizado aqui ou ali, nunca está nas mãos de alguns, nunca é apropriado como uma riqueza ou um bem." (FOUCAULT, 1999, p. 102). O poder se dá por meio de relações, relações de poder e, por isso, circula, se exerce em redes. Tais redes atingem as mais variadas esferas sociais e relações, como a produção de conhecimento, a constituição da verdade e a formação dos indivíduos. Para o filósofo, não é o indivíduo cognoscente que produz um saber que serve, ou não ao poder, "[...] mas o poder-saber, os processos e as lutas que o atravessam e que o constituem, que determinam as formas e os campos possíveis do conhecimento". (FOUCAULT, 1999, p. 31).

Assim, por meio da História da Matemática é possível encontrar outros modos de matematizar, outros jogos de linguagem, produzidos por culturas e formas de vida em diferentes tempos e espaços, e que foram deixados à margem da Matemática Acadêmica. Por estarem à margem, possivelmente não abordados pelos professores em sala de aula, mesmo que em algum caso possa existir semelhanças de família em ambos os modos de matematizar. Por meio da Etnomatemática, é possível analisar como esses saberes, tanto os hegemônicos quanto os marginalizados foram gerados, organizados e difundidos, criando-se assim, condições que possibilitam compreender as relações de poder-saber envolvidas nessa trama histórica.

Mais do que isso, como mostra Lara (2013) em seus estudos, a articulação de ambas as tendências pode criar condições que possibilitem aos estudantes compreender os processos de geração, organização e difusão do conhecimento matemático, além de outras formas de matematizar que foram marginalizadas ao longo da história devido às relações de poder e saber. Para a autora, por meio da História da Matemática o estudante poderá investigar como os sujeitos foram atravessados "[...] por relações de poder e de luta, para compreender de que modo determinado conhecimento e não outro foi gerado, porque ele foi organizado de um modo e não de outro, em determinado momento e não em outro." (LARA, 2013, p. 55). Tem-se como premissa que a compreensão de tais aspectos contribui para a aprendizagem dos estudantes, ademais mostra-Ihes que a Matemática é uma construção social, pautada nas necessidades dos povos e civilizações da antiguidade, criando nas crianças a percepção de que há outros modos de matematizar, distintos do ensinado nas escolas.

\section{ASPECTOS METODOLÓGICOS}

A fim de oportunizar aos estudantes condições que possibilitem compreender que a Matemática ensinada na escola é uma forma de matematizar que se tornou hegemônica devido às relações de poder e saber históricas, elaborou-se uma proposta de ensino que articula a Etnomatemática e a História da Matemática para o ensino da multiplicação. A proposta foi realizada ao longo 
de 2018 em um único encontro de $4 \mathrm{~h}$, com dezoito estudantes do $5^{\circ}$ ano do Ensino Fundamental de uma escola pública da cidade de Porto Alegre, RS.

O principal objetivo da proposta foi criar condições para que os estudantes refletissem acerca dos diversos métodos e algoritmos, desenvolvidos ao longo da História da Matemática, para a realização de algoritmos de multiplicação. Os objetivos específicos delineados para tal foram: conhecer as principais características das civilizações da antiguidade que possibilitaram a criação de seus métodos específicos para a realização da multiplicação; apresentar diversas formas de matematizar históricos, ou seja, jogos de linguagem utilizados por distintos povos e civilizações da antiguidade, para a realização do algoritmo da multiplicação; resolver exercícios de multiplicação utilizando as formas de matematizar de distintas formas de vida; compreender as vantagens/ desvantagens de cada modo de matematizar; comparar as formas de matematizar históricas com a forma de matematizar ensinado na escola.

A opção metodológica aproxima-se do proposto por Lara (2013), que apresenta três abordagens distintas para a História da Matemática nas salas de aula da Educação Básica, tendo como pano de fundo, seu entendimento acerca da relação intrínseca com a Etnomatemática. Das três abordagens, esse artigo ancora-se na primeira delas, que se baseia no estudo do processo de constituição histórica de um conceito específico, nesse caso a multiplicação. Assim, sem delimitar tempo, espaço ou civilização, apenas o conteúdo matemático, se estuda como se deu a constituição histórica do conceito em questão, nomes envolvidos, civilizações, época, contexto, motivações e as condições de possibilidade para o desencadeamento desse processo de constituição (LARA, 2013)

O material utilizado para a análise foi constituído das respostas fornecidas pelos estudantes a um questionário aplicado ao final da proposta de ensino. A fim de criar condições para que cada estudante expusesse seu pensamento, o questionário foi elaborado para que as respostas fossem dissertativas, pois entende-se que desse modo os participantes podem argumentar e justificar suas respostas. Após a organização, leitura e imersão nos dados, utilizou-se como ferramenta analítica a genealogia foucaultiana.

Para Foucault (1987), o objetivo da análise genealógica é, para Foucaut (1987, p. 31):

[...] compreender o enunciado na estreiteza e singularidade de sua situação; de determinar as condições de sua existência, de fixar seus limites de forma mais justa, de estabelecer suas correlações com os outros enunciados a que pode estar ligado, de mostrar que outras formas de enunciação excluí.

Diante disso, as respostas dos estudantes ao questionário são utilizadas como enunciações, no sentido foucaultiano do termo: "A enunciação é um acontecimento que não se repete; tem uma singularidade situada e datada que não se pode reduzir." (FOUCAULT, 1987, p. 116). Por meio dessa ferramenta analítica, é possível trazer à tona os discursos que determinaram a produção dos enunciados e enunciações e, mais do que isso, as condições de existência do próprio discurso. Isso pois, para Foucault (1987): 
irredutíveis à língua e ao ato da fala. É esse "mais" que preciso fazer aparecer e que é preciso descrever. (p. 56).

Para destacar tais enunciações serão elaborados diferentes quadros, nos quais constam parte dessas enunciações, uma vez que as repetidas não serão apresentadas. A identificação do estudante será apresentada no formato Ey, onde E caracteriza os estudantes e y representa um estudante participante específico. Na seção a seguir, a proposta de ensino será apresentada de modo sucinto para que na próxima seção se apresente as enunciações dos estudantes juntamente com a análise realizada.

\section{A PROPOSTA DE ENSINO}

A proposta de ensino abordou formas de matematizar distintas do algoritmo convencional, presente nos jogos de linguagem da Matemática Escolar, utilizando, para isso, métodos relacionados às formas de vida chinesa, hindu e egípcia. Dando início à proposta, apresentou-se aos estudantes o modo de matematizar próprio da forma de vida egípcia. De acordo com Eves (2004) já no Papiro de Rhind, documento egípcio datado de 1650 a. C., que contém 85 problemas matemáticos, há menção ao modo egípcio para a realização de operações de multiplicação:

O papiro Rhind é uma fonte primária rica sobre a matemática egípcia antiga; descreve os métodos de multiplicação e divisão dos egípcios, o uso que faziam das frações unitárias, seu emprego da regra de falsa posição, sua solução para o problema da determinação da área de um círculo e muitas aplicações da matemática a problemas práticos. (EVES, 2004, p. 70).

Segundo Eves (2004), os problemas tratados no Papiro representavam situações práticas vividas pelos egípcios naquela época, como a divisão de grãos de cevada entre homens trabalhadores, balanceamento de ração para animais e armazenamento de grãos.

De acordo com Roque (2012), um dos problemas poderia ser o seguinte: supondo que cada pessoa tenha direito a doze sacos de grãos, a quantos sacos um grupo de vinte e sete pessoas teria direito? Vê-se que uma das operações matemáticas possíveis para a resolução do problema é $12 \times 27$. Para a realização desse procedimento os egípcios construíam duas colunas, e realizavam duplicações sucessivas, linha após linha, do seguinte modo:

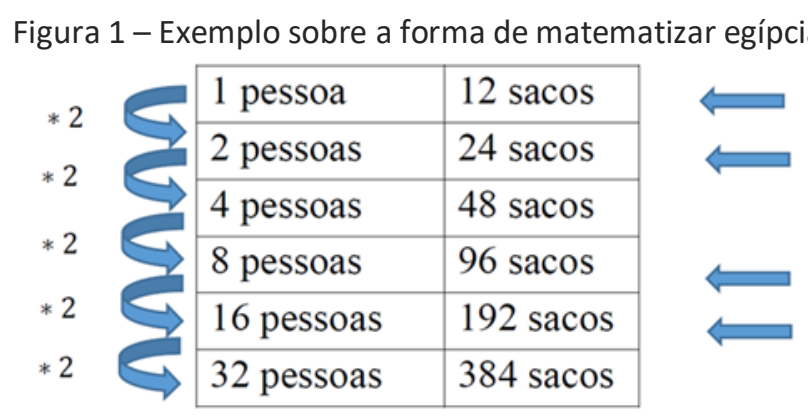

Fonte: Adaptação de Roque (2012). Autoria própria (2019).

Ao realizar as duplicações sucessivas, não se encontra quanto, de fato, ganhariam as 27 pessoas. Porém, sabe-se que as vinte sete pessoas ganharão o 
equivalente à soma de 1 pessoa +2 pessoas +8 pessoas +16 pessoas $(1+2+$ $8+16=27)$. Portanto, 27 pessoas ganharão 12 sacos +24 sacos +96 sacos +192 sacos $=12+24+96+192=324$ sacos.

Como destaca Eves (2004), "[...] a multiplicação e a divisão eram em geral efetuadas por uma sucessão de duplicações com base no fato de que todo número pode ser representado por uma soma de potências de 2." (EVES, 2004, p. 72). Assim, a forma de matematizar egípcia, tanto para a multiplicação quanto para a divisão, elimina a necessidade de aprender a tabuada para valores diferentes de 2 .

Na sequência da proposta, foi apresentado aos estudantes uma das formas de matematizar próprias da civilização hindu, denominada Gelósia. De acordo com Boyer (1974), os indianos mantinham certo fascínio pelo trabalho com números, em especial as operações e a resolução de equações. O método da Gelósia recebe esse nome em meados do século XV, na Itália, por utilizar como base para o desenvolvimento do método uma figura semelhante às grades colocadas em janelas. Entretanto, é possível encontrar esse método com outros nomes, como multiplicação em reticulado ou multiplicação em grade (BOYER, 1974). Não se sabe ao certo quando ou onde essa forma de matematizar apareceu, porém, os registros históricos do século XII permitem concluir que essa matematização iniciou na Índia. De acordo com Boyer (1974), para o desenho da Gelósia era utilizada uma pequena tábua com farinha branca ou areia.

O método consiste em criar um grande quadro (Gelósia) em que o número de colunas e linhas do quadro corresponde à quantidade de algarismos dos números que serão multiplicados. Feito o quadro, deve-se traçar diagonais em todas as celas formadas pelo encontro da coluna com a linha. Ao traçar as diagonais, as celas se transformam em triângulos, espaços nos quais serão escritos os resultados das pequenas multiplicações que serão realizadas, ficando a dezena na parte superior e a unidade na parte inferior.

As etapas que compõem o método da Gelósia podem ser sintetizadas do seguinte modo: constrói-se um Quadro com duas linhas e duas colunas (quantidades relativas aos algarismos de cada multiplicador); traçam-se as diagonais de cada cela formada; realizam-se as multiplicações em cada cela da Gelósia, posicionando a unidade na parte inferior e a dezena na parte superior; soma-se os valores em cada diagonal, começando da direita para a esquerda. Assim, utilizando-se da mesma situação mencionada por Roque (2012) para a forma de matematizar egípcia, o produto de 12 por 27 por meio da Gelósia ocorre do seguinte modo:

Figura 2 - Exemplo sobre o método da Gelósia

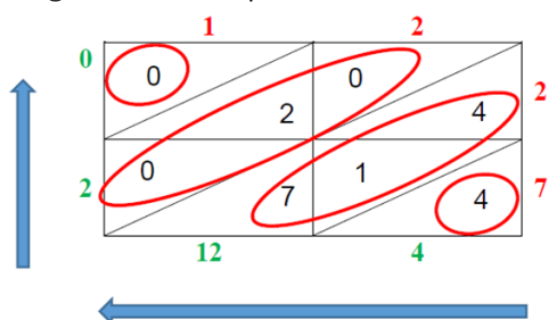

Fonte: Autoria própria (2019). 
Assim, como no modo de matematizar próprio da Matemática Escolar, devido ao fato do sistema de numeração ser decimal, ao efetuar as somas devese seguir as regras em relação à quantidade de unidades, dezenas, centenas e assim por diante. Observam-se semelhanças de família entre o modo de matematizar escolar e o modo de matematizar presente no método da Gelósia: quando soma-se 10 unidades, estas são convertidas em uma dezena; quando soma-se 10 dezenas, estas são convertidas em uma centena; e assim por diante. O produto final pode ser encontrado como demonstrado na Figura 3:

Figura 3 - Fim do exemplo sobre o método da Gelósia

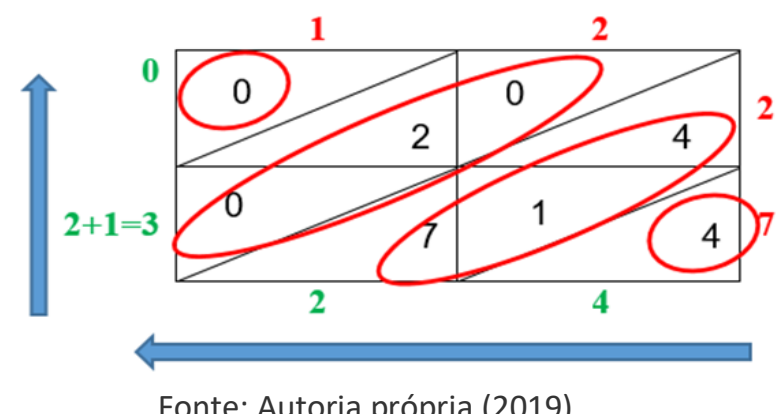

Conforme Eves (2004): "A simplicidade de sua aplicação poderia tê-lo mantido em uso até hoje, não fora a necessidade de imprimir, ou desenhar, uma rede de segmentos de reta." (EVES, 2004, P. 323). Já Boyer (1974) destaca:

O princípio fundamental da multiplicação em gelósia evidentemente é o
mesmo da nossa, o arranjo em células sendo apenas um estratagema
conveniente para aliviar a concentração mental necessária ao "transportar"
de lugar para lugar as dezenas que aparecem nos produtos parciais. O único
"transporte" necessário na multiplicação em reticulado aparece nas adições
finais ao longo das diagonais. (BOYER, 1974, p. 158).

Por fim, o modo próprio de matematizar da civilização chinesa foi apresentado aos estudantes. De acordo com Eves (2004), o método chinês era realizado com varetas de bambu, de modo que, dependendo dos números que se pretende multiplicar, é preciso um número razoável de varetas. Inicialmente, colocam-se as varetas de bambu em quantidade correspondente às unidades, dezenas e centenas dos números que se pretende multiplicar, de modo que as varetas do multiplicando fiquem no sentido vertical e do multiplicador no sentido horizontal. As varetas devem ficar sobrepostas pois o método depende dos pontos de encontro entre as varetas nos sentidos horizontal e vertical, como pode ser observado no exemplo abaixo, no qual pretende-se calcular o produto entre 35 e 43.

Figura 4 - Exemplo sobre a forma de matematizar chinesa

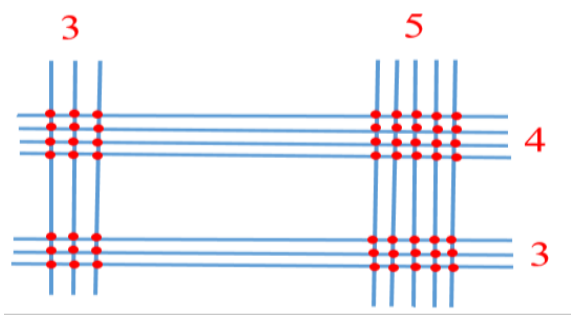

Fonte: Autoria própria (2019). 
O próximo passo é somar a quantidade de pontos de encontro, porém de modo que as unidades, dezenas e centenas sejam evidenciadas. Para isso, dividese a figura em diagonais, começando da direita para a esquerda, de modo que a primeira intersecção de varetas corresponde a uma diagonal, a segunda intersecção de varetas, tanto para cima, quanto para o lado esquerdo, corresponde a segunda diagonal, e assim sucessivamente. De modo semelhante aos demais processos, sempre que a quantidade de unidades exceder nove, deve-se manter a unidade na diagonal atual e acrescentar quantas unidades forem necessárias na diagonal à esquerda. A imagem expressa na figura abaixo mostra o processo:

Figura 5 - Fim do exemplo sobre a forma de matematizar chinesa

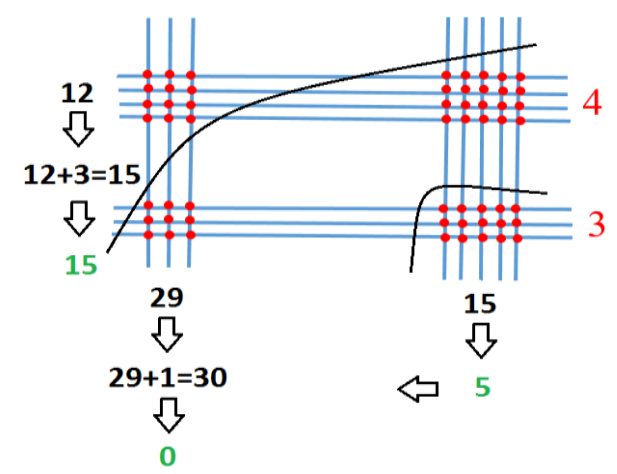

Fonte: Autoria própria (2019).

Após a apresentação e discussão sobre os diferentes modos de matematizar, os estudantes foram convidados a praticar. Para isso, foi sugerido que cada estudante elaborasse exemplos de cálculos e os realizasse utilizando os modos de matematizar abordados na proposta de ensino. Para tal, foram fornecidas folhas quadriculadas, que auxiliaram na construção de alguns métodos, como o chinês e a Gelósia. Durante esse período, os estudantes puderam ter contato com os livros de História da Matemática, tanto para ler mais sobre a história relacionada aos métodos apresentados, como para verificar novamente como se realizam os métodos. Para concluir este momento, solicitou-se que os estudantes expressassem verbalmente quais dificuldades e facilidades tiveram para resolver cada método.

Para finalizar a proposta de ensino, os estudantes foram convidados a expressar verbalmente quais as semelhanças e diferenças identificadas em relação ao modo de matematizar da Matemática Escolar. Após esse momento de reflexão e discussão, os estudantes responderam ao questionário acerca da atividade desenvolvida, que foi o instrumento para coleta dos dados aqui analisados.

\section{RESULTADOS E DISCUSSÕES}

Inicialmente, buscou-se investigar junto aos estudantes se eles enfrentam dificuldades para realizar a operação de multiplicação. Para tal, lhes foi proposta a seguinte questão: você sente alguma dificuldade para realizar as contas de multiplicação, quando devem ser realizadas sem a calculadora? Algumas das respostas fornecidas pelos estudantes podem ser observadas no Quadro 1: 
Quadro 1 - Primeira questão analisada

\begin{tabular}{|c|c|c|c|}
\hline \multirow{2}{*}{ Autor } & $\begin{array}{c}\text { Você sente alguma dificuldade para realizar } \\
\text { contas de multiplicação, quando devem ser } \\
\text { realizadas sem a calculadora? Comente sua } \\
\text { resposta. }\end{array}$ & $\begin{array}{c}\text { Enunciações } \\
\text { semelhantes }\end{array}$ & Frequência \\
\hline$E_{4}$ & $\begin{array}{c}\text { Não, eu não uso a calculadora e eu faço a conta e } \\
\text { gosto de fazer a prova real. }\end{array}$ & $E_{11,} E_{18}$ & 3 \\
\hline$E_{7}$ & $\begin{array}{c}\text { Às vezes por que é confuso e tem vários números } \\
\text { e tem que saber muito a tabuada, mas para mim } \\
\text { até é fácil. }\end{array}$ & 5 \\
\hline$E_{8}$ & $\begin{array}{c}\text { Não. Porque eu adoro matemática. Eu sei toda } \\
\text { tabuada e não é difícil de multiplicar. }\end{array}$ & $E_{1, E_{12}, E_{14}, E_{16}}$ & 5 \\
\hline$E_{9}$ & Sim, ainda mais com contas de três algarismos. & $E_{3,} E_{5}, E_{6}, E_{17}$ & 5 \\
\hline$E_{13}$ & $\begin{array}{c}\text { Sinto um pouco de dificuldade para multiplicar, } \\
\text { acho um pouco difícil. }\end{array}$ & $\mathrm{E}_{10}$ & 2 \\
\hline $\mathrm{E}_{15}$ & $\begin{array}{c}\text { Às vezes sinto um pouco de dificuldade, me } \\
\text { confundo porque tem vários números e divido } \\
\text { errado. }\end{array}$ & $\mathrm{E}_{2}$ & 2 \\
\hline
\end{tabular}

Fonte: Autoria própria (2019).

Os ditos trazem à tona que a maioria dos estudantes não possui dificuldades ou possui pouca dificuldade para realizar contas de multiplicação, evidenciando, inclusive, certo carinho pela Matemática. Independente do posicionamento assumido pelos estudantes no que se refere às suas dificuldades ou facilidades, destacam-se alguns fatores mencionados como produtores de dificuldades: cálculos com vários algarismos e a necessidade de utilizar a tabuada.

Dando continuidade, os estudantes responderam à questão expressa no Quadro 2:

Quadro 2 - Segunda questão analisada

\begin{tabular}{|c|c|c|c|}
\hline Autor & $\begin{array}{l}\text { Qual a sua opinião sobre conhecer outros } \\
\text { métodos para a realização de contas de } \\
\text { multiplicação: }\end{array}$ & $\begin{array}{l}\text { Enunciações } \\
\text { semelhantes }\end{array}$ & Frequência \\
\hline $\mathrm{E}_{1}$ & $\begin{array}{l}\text { Útil, assim pude aprimorar a minha multiplicação e } \\
\text { conhecer coisas novas. Interessante e necessário. }\end{array}$ & & 1 \\
\hline$E_{3}$ & Eu achei bem difícil e complicado pra mim. & & 1 \\
\hline $\mathrm{E}_{4}$ & $\begin{array}{c}\text { Eu gostei dessas novas técnicas é muito legal eu } \\
\text { amei e eu achei fácil. }\end{array}$ & $\mathrm{E}_{11}, \mathrm{E}_{12}, \mathrm{E}_{14}$ & 4 \\
\hline $\mathrm{E}_{7}$ & $\begin{array}{l}\text { Achei muito difícil mas quando aprende bem é } \\
\text { mais legal. }\end{array}$ & & 1 \\
\hline $\mathrm{E}_{9}$ & $\begin{array}{l}\text { Eu achei legal, diferente e estranho, achei alguns } \\
\text { difíceis. }\end{array}$ & $E_{2}, E_{15}$ & 3 \\
\hline$E_{10}$ & Gostei muito porque não é enjoativo. & $E_{16}$ & 2 \\
\hline$E_{13}$ & $\begin{array}{l}\text { Achei muito mais simples com esse jeito do que } \\
\text { com os outros jeitos }\end{array}$ & $E_{17}$ & 2 \\
\hline $\mathrm{E}_{18}$ & Eu achei bem legal, interessante, divertido. & $\mathrm{E}_{5}, \mathrm{E}_{6}, \mathrm{E}_{8}$ & 4 \\
\hline
\end{tabular}

Fonte: Autoria própria (2019).

Observa-se que apenas $E_{3}$ considerou os modos de matematizar de outras civilizações difícil e complicado, ao passo que a maioria dos estudantes avaliou positivamente a proposta. O Quadro 2 evidencia que a maioria dos estudantes julgou a atividade interessante, fácil, diferente, legal e divertida. Mais do que isso, alguns estudantes destacaram a importância de conhecer novos métodos e 
o quanto tais estratégias não são "enjoativas". Destaca-se o dito de $E_{1}$, pois afirma que por meio da proposta de ensino foi possível aprimorar seu entendimento acerca do algoritmo da multiplicação escolar, e $E_{13}$, que considerou os modos de matematizar apresentados na proposta de ensino mais simples. Esse mesmo estudante afirmou ter um pouco de dificuldade para realizar o algoritmo da multiplicação nos moldes da escola, como foi possível observar no Quadro 1. Por fim, cabe destacar, que entre os estudantes que avaliaram de modo positivo, alguns mencionaram que determinados métodos foram difíceis de compreender, como por exemplo, nos ditos de $E_{9}$ e $E_{7}$.

De modo geral, as afirmações dos estudantes trazem à tona um argumento que pesquisadores do campo, como Miguel (1993) já anunciaram: a História da Matemática é uma fonte de motivação para os processos de ensino e de aprendizagem. Portanto, tem-se como um efeito da proposta de ensino, que o contato com modos de matematizar distintos dos jogos de linguagem da Matemática Escolar pode motivar os estudantes. É relevante retomar a discussão já feita por Miguel (1993), de que o caráter motivacional da História não está necessariamente associado à História da Matemática, mas em uma abordagem pedagógica diferenciada, que foge do disciplinamento no qual os corpos estão submetidos.

A instituição escola ao mesmo tempo em que regula e disciplina os estudantes, é regulada por relações de poder-saber que determinam, entre outros, os conteúdos e métodos considerados adequados para o ensino. Desse modo, os controles instituídos pela escola são resultados de relações de poder e saber e são exercidos sobre variadas instâncias, como o currículo, as estratégias de ensino, o comportamento dos estudantes, entre outros (VEIGA-NETO, 2014). Estabelecem-se, então, os jogos de linguagem considerados adequados, os jogos de linguagem da Matemática Escolar, e acaba-se por marginalizar outros jogos de linguagem, como as outras formas de matematizar apresentadas na proposta de ensino.

A importância do reconhecimento de outras formas de matematizar e de outros jogos de linguagem, é reforçada nas questões a seguir que, embora semelhantes, objetivam analisar especificidades distintas. A primeira delas se refere à facilidade de entendimento dos métodos (Quadro 3), ao passo que na segunda (Quadro 4), objetiva-se compreender a facilidade para a aplicação.

Quadro 3 - Terceira questão analisada

\begin{tabular}{|c|c|c|c|}
\hline Autor & $\begin{array}{c}\text { Comparando o algoritmo de multiplicação } \\
\text { aprendido na escola com as técnicas } \\
\text { desenvolvidas por outras civilizações, qual/quais } \\
\text { você acha de mais fácil ENTENDIMENTO? } \\
\text { Justifique sua resposta: }\end{array}$ & $\begin{array}{c}\text { Enunciações } \\
\text { semelhantes }\end{array}$ & Frequência \\
\hline$E_{3}$ & $\begin{array}{c}\text { Eu achei mais fácil o método da Gelósia por que eu } \\
\text { entendi rápido. }\end{array}$ & $E_{12,} E_{15}, E_{16}$ & 4 \\
\hline$E_{6}$ & A que eu já sabia. & $E_{5}$ & 2 \\
\hline$E_{8}$ & $\begin{array}{c}\text { Eu achei mais fácil o modo egípcio porque é só } \\
\text { multiplicar o número. }\end{array}$ & $E_{1}, E_{14}$ & 3 \\
\hline$E_{9}$ & $\begin{array}{c}\text { Eu gostei do método da Gelósia porque ele é } \\
\text { divertido. }\end{array}$ & & 1 \\
\hline$E_{10}$ & $\begin{array}{c}\text { Eu gostei do método da Gelósia porque é mais fácil } \\
\text { e não precisa fazer conta. }\end{array}$ & $E_{2,}, E_{4}, E_{7}$ & 4 \\
\hline$E_{11}$ & Nenhum dos dois. & & 1 \\
\hline
\end{tabular}




\begin{tabular}{|c|c|c|c|}
\hline Autor & $\begin{array}{c}\text { Comparando o algoritmo de multiplicação } \\
\text { aprendido na escola com as técnicas } \\
\text { desenvolvidas por outras civilizações, qual/quais } \\
\text { você acha de mais fácil ENTENDIMENTO? } \\
\text { Justifique sua resposta: }\end{array}$ & $\begin{array}{c}\text { Enunciações } \\
\text { semelhantes }\end{array}$ & Frequência \\
\hline $\mathrm{E}_{13}$ & $\begin{array}{c}\text { Eu achei a técnica chinesa porque eu entendi } \\
\text { melhor é mais divertido. }\end{array}$ & 1 \\
\hline $\mathrm{E}_{17}$ & $\begin{array}{r}\text { Achei mais fácil a que a profo Juliana ensinou } \\
\text { porque não é complicado. }\end{array}$ & 1 \\
\hline $\mathrm{E}_{18}$ & $\begin{array}{c}\text { Eu gostei bastante de todas, como eu aprendi } \\
\text { primeiro e já sei o método normal ele é mais fácil } \\
\text { de entender. }\end{array}$ & \\
\hline
\end{tabular}

Fonte: Autoria própria (2019).

As respostas evidenciam que um estudante julgou que nenhuma das duas técnicas é de mais fácil entendimento, enquanto outros três estudantes consideraram de mais fácil entendimento o algoritmo da multiplicação expresso por meio dos jogos de linguagem da Matemática Escolar. Entre os demais, a maioria avaliou o método da Gelósia de mais fácil entendimento, em especial por ser mais simples, legal e divertido, como é evidente no Quadro acima.

É relevante destacar que para $E_{10}$, para quem os modos de matematizar abordados na proposta de ensino não são "enjoativos", como foi observado no Quadro 1, o método da Gelósia é mais fácil pois não requer a realização de contas. Observa-se, no dito deste estudante, que ele só considera 'conta' o modo de matematizar que utiliza as regras e os jogos de linguagem da Matemática Escolar.

Isso pode ser efeito do que Lara (2001) chamou de poder disciplinador da Matemática, que busca uma única forma de matematizar, subjetivando, regulando e normalizando os estudantes. Como destaca a autora, a Matemática é "[...] um conjunto de conhecimentos para o controle minucioso do modo de pensar, raciocinar e agir do/a aluno/a e que é através da imposição e sujeição a esse modo de pensar que se produzem determinadas habilidades mentais." (LARA, 2001, p. 29).

Portanto, por meio da História da Matemática, em especial a partir do uso de diferentes modos de matematizar historicamente propostos, pode-se criar condições de possibilidade para desmistificar a supremacia dos jogos de linguagem da Matemática Escolar. Ao professor cabe enfatizar que os diferentes modos de matematizar são eficazes, propondo reflexões acerca de seus limites e vantagens, sem utilizar a História da Matemática apenas como uma fonte a ser utilizada de modo mecânico nos processos de ensino e de aprendizagem.

Apesar dos ditos de alguns estudantes evidenciarem o disciplinamento no qual estão imersos, pode-se observar que um dos efeitos da proposta de ensino, além de desmistificar a supremacia de uma única forma de matematizar, foi proporcionar a aprendizagem da multiplicação. Isso pode ser observado ao longo dos ditos de $E_{9}$, que sente dificuldades em realizar o produto de números com três algarismos (Quadro 1), mas entendeu o produto por meio da Gelósia, pois é "divertido" (Quadro 3). 
Após questionar os estudantes acerca da facilidade de compreensão dos métodos, objetivou-se indagar acerca da facilidade de aplicação dos métodos, ou em outras palavras, verificar a praticidade na realização dos cálculos.

\section{Quadro 4 - Quarta questão analisada}

\begin{tabular}{|c|c|c|c|}
\hline Autor & $\begin{array}{c}\text { Comparando o algoritmo de multiplicação } \\
\text { aprendido na escola com as técnicas } \\
\text { desenvolvidas por outras civilizações, qual/quais } \\
\text { você acha de mais fácil APLICAÇÃO? Justifique sua } \\
\text { resposta:3 }\end{array}$ & $\begin{array}{c}\text { Enunciações } \\
\text { semelhantes }\end{array}$ & Frequência \\
\hline$E_{1}$ & $\begin{array}{c}\text { Eu penso no da escola, pois achei mais fácil a minha } \\
\text { compreensão. }\end{array}$ & $\begin{array}{c}E_{5,}, E_{6}, E_{7}, E_{12,} \\
E_{15}\end{array}$ & 6 \\
\hline$E_{8}$ & Eu achei mais fácil o modo egípcio porque é só \\
multiplicar o número. & & 1 \\
\hline$E_{9}$ & O que eu aprendi hoje. & $E_{13}, E_{17}$ & 3 \\
\hline$E_{14}$ & O método chinês. & $E_{2}$ & 2 \\
\hline$E_{16}$ & A mais fácil eu acho a Gelósia. & $E_{3}, E_{4}, E_{10}$ & 4 \\
\hline
\end{tabular}

Fonte: Autoria própria (2019).

Observa-se nesses distintos posicionamentos, desde estudantes que preferiram algum modo de matematizar diferente do escolar, a estudantes que optaram pelo algoritmo da multiplicação presente nos jogos de linguagem da Matemática Escolar. No entanto, observa-se um crescimento em relação aos estudantes que preferem o algoritmo em seus jogos de linguagem escolares. Novamente, tais ditos podem evidenciar um disciplinamento, efeito do poder da Matemática, entretanto, pode indicar que os estudantes reconhecem que, apesar de algumas formas de matematizar das civilizações passadas serem de mais fácil entendimento, o algoritmo convencional, presente nos jogos de linguagem da Matemática Escolar, é de mais fácil aplicação.

Em uma perspectiva wittgensteiniana, pode-se dizer que esses estudantes já dominam um jogo, o jogo da Matemática Escolar, e por esse motivo, estão capturados pelas suas regras e seus modos de matematizar. Ou seja, apesar de julgarem os métodos históricos de mais fácil entendimento, acreditam que o método da Matemática Escolar é de mais fácil aplicação, por já estarem imbricados nos jogos de linguagem e nas regras da Matemática Escolar, como pode ser percebido nos ditos de $E_{7}$ e $E_{12}$. Como destaca Wittgenstein (1979), "[...] diremos apenas que aprende seu uso quando o lugar já está preparado. E está preparado aqui não porque aquele para quem damos a elucidação já sabe as regras, mas porque, em outro sentido, já domina um jogo." (p. 22).

O reconhecimento de outros jogos de linguagem, específicos de cada forma de vida, como os modos de matematizar de outras civilizações para a operação de multiplicação, não almeja desqualificar o algoritmo convencional proposto pela Matemática Escolar. O propósito desse reconhecimento é possibilitar ao estudante opções, métodos e formas diferenciadas para conduzir a realização dos algoritmos de multiplicação.

Na sequência do questionário objetivou-se compreender se o conhecimento de outros modos de matematizar modificou algo no modo de pensar dos estudantes. Observa-se que onze estudantes afirmaram que modificou sua forma de pensar, enquanto cinco afirmam que conhecer outras formas de matematizar 
em nada modificou sua forma de pensar. Entre as justificativas manifestadas pelos estudantes, destacam-se as presentes no Quadro 5.

Quadro 5-Quinta questão analisada

\begin{tabular}{|c|c|c|c|}
\hline Autor & $\begin{array}{c}\text { Conhecer outros modos de realizar contas de } \\
\text { multiplicação mudou algo em sua forma de } \\
\text { pensar? }\end{array}$ & $\begin{array}{c}\text { Enunciações } \\
\text { semelhantes }\end{array}$ & Frequência \\
\hline$E_{1}$ & Sim, passei a ver e entender melhor. & $E_{2}, E_{13}, E_{16}$ & 4 \\
\hline$E_{3}$ & Não mudou. & $E_{5}, E_{6}, E_{12}$ & 4 \\
\hline$E_{4}$ & Sim, mudou o jeito de fazer as contas. & $E_{9}, E_{10}$ & 3 \\
\hline$E_{7}$ & $\begin{array}{c}\text { Muito, nunca pensei que ia aprender contas } \\
\text { diferentes. }\end{array}$ & $E_{11}$ & 2 \\
\hline$E_{8}$ & $\begin{array}{c}\text { Mudou, no método egípcio mudou muito de } \\
\text { agora porque antes era só por 2 e agora por } \\
\text { todos. }\end{array}$ & & 1 \\
\hline$E_{14}$ & $\begin{array}{c}\text { Não, até me ajudam a fazer mais fácil e eu não me } \\
\text { confundir na hora de fazer. }\end{array}$ & 1 \\
\hline$E_{15}$ & Um pouco, mas não muito. & & 1 \\
\hline
\end{tabular}

Fonte: Autoria própria (2019).

$O$ respondente $E_{14}$ afirmou que não houve mudanças no seu modo de pensar, no entanto, reconhece que os modos de matematizar tratados na proposta de ensino o ajudam a fazer de modo mais fácil a multiplicação, bem como, evitam confusão no momento da realização do produto. É interessante destacar que esse estudante respondeu, na primeira questão analisada, que não tem dificuldades na realização de contas de multiplicação, porém, na quinta questão analisada, reconhece que os modos de matematizar abordados podem evitar que o mesmo se confunda na realização do produto. Diante disso, pode-se avaliar de modo positivo a realização da proposta inclusive para aqueles estudantes que não possuem dificuldades no uso das regras provenientes dos jogos de linguagem da Matemática Escolar.

Entre os estudantes que responderam positivamente à questão, observa-se que $E_{7}$ e $E_{13}$, que apresentavam dificuldades na operacionalização dos jogos de linguagem da Matemática Escolar (Quadro 1), argumentaram que a proposta de ensino mudou sua forma de pensar. $\mathrm{E}_{13}$ avalia que foi possível raciocinar melhor, enquanto $E_{7}$ afirma que não imaginava ser possível aprender contas diferentes.

$\mathrm{O}$ dito de $\mathrm{E}_{7}$ traz à tona algo comum entre estudantes da Educação Básica: $\mathrm{O}$ entendimento de que só existe um modo de fazer Matemática, um único modo de matematizar. Tal pensamento é fruto de um discurso que prioriza o modo de matematizar padrão, adotado pela Matemática Acadêmica, sem reconhecer outras formas de fazer Matemática, outras práticas e regras. Esse discurso associa-se ao que Foucault intitulou de sociedade disciplinar, na qual o controle se dá por meio "[...] técnicas para assegurar a ordenação das multiplicidades humanas." (FOUCAULT, 1999, p. 241). Tais técnicas, chamadas de disciplina, "[...] permitem ajustar [...] a multiplicidade dos homens e a multiplicidade dos aparelhos de produção (e como tal, deve-se entender não só "produção" propriamente dita, mas a produção de saber e de aptidões na escola [...]" (FOUCAULT, 1999, p. 242). De acordo com Lara (2011), "[...] no âmbito do ensino da Matemática podemos afirmar que na sociedade disciplinar se buscava uma homogeneização dos indivíduos, ou seja, homogeneização nas suas formas de pensar." (LARA, 2011, p. 108). 
Observa-se, entre os efeitos da proposta de ensino, a possibilidade de rompimento desse modo de pensar padrão, visto que entre as justificativas listadas pelos estudantes, destaca-se o reconhecimento de que existem formas diferentes para realizar a mesma operação. Portanto, pode-se inferir que a proposta de ensino criou condições para que os estudantes pudessem reconhecer que existem outros modos de matematizar, outros jogos de linguagem constituídos de regras específicas e com semelhanças de família em relação aos jogos de linguagem da Matemática Escolar. Esses outros jogos de linguagem conduzem para o mesmo resultado no que tange à operação de multiplicação, porém por meio de regras distintas, relacionadas às formas de vida nas quais foram gerados.

Na sequência da proposta de ensino, os estudantes foram questionados se utilizariam algum dos modos de matematizar abordados na proposta de ensino, ao longo da sua vida acadêmica. Algumas das respostas fornecidas encontram-se no Quadro 6.

Quadro 6 - Sexta questão analisada

\begin{tabular}{|c|c|c|c|}
\hline Autor & $\begin{array}{l}\text { Você usaria algum dos métodos antigos para } \\
\text { realizar multiplicações? Justifique sua } \\
\text { resposta: }\end{array}$ & $\begin{array}{l}\text { Enunciações } \\
\text { semelhantes }\end{array}$ & Frequência \\
\hline $\mathrm{E}_{1}$ & Talvez, depende. & & 1 \\
\hline$E_{2}$ & $\begin{array}{l}\text { Sim, o método da Gelósia, pois é mais fácil e } \\
\text { rápido. }\end{array}$ & & 1 \\
\hline $\mathrm{E}_{4}$ & $\begin{array}{l}\text { Sim, porque eles são mais fáceis de fazer e não } \\
\text { precisa muita conta. }\end{array}$ & $E_{3}, E_{13}$ & 3 \\
\hline$E_{5}$ & Não. & $E_{6}, E_{10}$ & 3 \\
\hline $\mathrm{E}_{8}$ & $\begin{array}{l}\text { Sim, porque o método egípcio é mais fácil de } \\
\text { multiplicar. }\end{array}$ & & 1 \\
\hline $\mathrm{E}_{9}$ & Não, porque eu não acho necessário. & & 1 \\
\hline $\mathrm{E}_{11}$ & Sim. & $\mathrm{E}_{16}$ & 2 \\
\hline $\mathrm{E}_{12}$ & $\begin{array}{l}\text { Eu acho que não pois eles têm mais contas que } \\
\text { o normal. }\end{array}$ & $E_{7}$ & 2 \\
\hline $\mathrm{E}_{14}$ & Eu acho que sim, só se a professora permitir. & & 1 \\
\hline
\end{tabular}

Fonte: Autoria própria (2019).

Dos 16 estudantes que responderam à questão, mais da metade afirmaram que utilizariam alguma das formas de matematizar abordadas na proposta de ensino, apenas um se posicionou em dúvida e o restante afirmou que não utilizariam.

Entre os estudantes que não utilizariam, é relevante destacar que $E_{9}$, embora tenha dificuldades em operacionalizar cálculos com três algarismos, como afirmou na primeira questão analisada, ainda assim não utilizaria algum dos métodos tratados na proposta, por não julgar necessário. Ou seja, apesar de ter dificuldades com o algoritmo da multiplicação nos moldes da Matemática Escolar e considerar o método da Gelósia fácil e "divertido", o estudante não julga necessário o seu uso. Tal comportamento pode ser fruto do discurso em prol da padronização imposta pela sociedade disciplinar, visto que não valoriza modos distintos de pensar, agir, matematizar, se posicionar, entre outros. Frequentemente se observa esse comportamento nos estudantes, que questionam a necessidade de aprender de outro modo uma vez que apenas um 
já é suficiente. Esse tipo de discurso ao se propagar, difundir e repetir, adquire um status de verdade que produz sujeitos que não valorizam a diversidade dos modos de pensar e agir, seja no domínio da Matemática, das metodologias de ensino, das técnicas de aprendizagem, das relações sociais.

$\mathrm{O}$ dito de $\mathrm{E}_{14}$ evidencia relações de poder-saber entre professor e estudante, visto que a utilização de outras formas de matematizar está sujeita à aprovação do professor. Observa-se um estudante capturado pelo discurso de que o professor é o detentor do conhecimento e, portanto, quem tem a capacidade de avaliar entre o correto e errado, o verdadeiro ou o falso no que diz respeito ao modo como se deve operacionalizar. Nesse discurso, quem impõe a norma é o professor, moldando os modos de agir e pensar dos estudantes. Como consequência, não há abertura para jogos de linguagem com regras distintas em relação à Matemática Escolar ou, quando há, estas são utilizadas como curiosidades ou anedotas, sem serem vistas como legítimas.

Por fim, a última questão (Quadro 7) a ser analisada, pretende avaliar as contribuições dos distintos modos de matematizar abordados para o entendimento dos jogos de linguagem e das regras da Matemática Escolar.

Quadro 7 - Sétima questão analisada

\begin{tabular}{|c|c|c|c|}
\hline Autor & $\begin{array}{c}\text { Conhecer outros modos para a realização de } \\
\text { contas de multiplicação permitiu que você } \\
\text { compreendesse melhor o algoritmo de } \\
\text { multiplicação aprendido na escola? De que modo? } \\
\text { Justifique sua resposta: }\end{array}$ & $\begin{array}{c}\text { Enunciações } \\
\text { semelhantes }\end{array}$ & Frequência \\
\hline$E_{1}$ & Bom, aprendi a revisar números, então sim. & & 1 \\
\hline$E_{2}$ & $\begin{array}{c}\text { Sim, alguns números eram muito grandes e difíceis } \\
\text { e eu não conseguia fazer. }\end{array}$ & $E_{9,} E_{14}, E_{16}$ & 4 \\
\hline$E_{3}$ & Sim, eu acho. & & 1 \\
\hline$E_{5}$ & Não. & $E_{6}, E_{12}$ & 3 \\
\hline$E_{7}$ & Acho que não, porque as suas contas são muito \\
\hline$E_{10}$ & Siferentes. & $E_{15}, E_{8}$ & 3 \\
\hline$E_{11}$ & Não mudou nada para mim apenas é mais fácil. & & 1 \\
\hline$E_{13}$ & Eu entendi bem melhor do que eu aprendi na & & 1 \\
\hline
\end{tabular}

Fonte: Autoria própria (2019).

Vale ressaltar, que embora, ao final da proposta de ensino, uma discussão a respeito das semelhanças e diferenças entre todos os modos de matematizar, escolar ou não, tenha sido realizada, dos 16 estudantes que responderam à questão, seis afirmaram que conhecer outros modos de matematizar não possibilitou compreender melhor o algoritmo convencional, presente nos jogos de linguagem da Matemática Escolar. Já os demais estudantes afirmam que sim, como foi possível verificar no Quadro 7. Novamente, destaca-se o dito de $E_{7}$ pois, segundo o estudante, não houve contribuições visto que as contas são distintas. Observa-se que o estudante não percebeu as semelhanças de família entre os jogos de linguagem abordados na proposta de ensino e os jogos de linguagem da Matemática Escolar.

Entretanto, os demais ditos evidenciam que a proposta de ensino criou condições que possibilitaram à maioria dos estudantes aprimorar suas técnicas e métodos para a realização do algoritmo da multiplicação. Isso ocorre devido às 
semelhanças de família presentes nas diferentes regras que compõem os jogos de linguagem apresentados aos estudantes. Diante disso, é papel do professor, ao mesmo tempo em que apresenta outros modos de matematizar, reforçar, sempre que possível, as semelhanças de família presentes entre diferentes jogos de linguagem. Isso pode ser feito de forma oral, durante a apresentação dos modos de matematizar escolhidos pelo professor. Pode-se destacar, por exemplo, as semelhanças entre o algoritmo convencional de multiplicação e: o modo de matematizar chinês, em que o uso do sistema decimal de contagem acarreta nas trocas entre unidade, dezena e centena; o método da gelósia, em que o processo é separado em etapas, iniciando-se à esquerda pelas unidades, e avançando para dezenas, centenas e assim por diante; o modo de matematizar egípcio, cuja estratégia de resolução utiliza a propriedade distributiva da multiplicação. No caso dessa proposta, tais semelhanças e dissemelhanças foram apontadas pelos estudantes. O professor auxiliou na articulação de termos específicos da Matemática Escolar que não estavam explícitos nos jogos de linguagem presentes nos outros métodos.

Um resultado semelhante foi encontrado por Silva e Trivizoli (2018), em um estudo que objetivou "[...] investigar as potencialidades da História da Matemática nos anos iniciais do Ensino Fundamental a partir da aplicação de uma atividade sobre sistemas de numeração." (SILVA, TRIVIZOLI, 2018, p. 336). Entre outros resultados, a proposta de ensino aplicada pelas pesquisadoras possibilitou aos estudantes, a partir da comparação entre o sistema de numeração hinduarábico e outros sistemas de numeração históricos, a percepção das "[...] vantagens e a consistência do sistema que utilizamos hoje." (SILVA, TRIVIZOLI, 2018, p. 352).

\section{CONSIDERAÇÕES FINAIS}

Ao longo dos anos iniciais do Ensino Fundamental, a base para o entendimento de conceitos e estruturas matemáticas necessárias aos demais anos escolares começa a ser desenvolvida. Tanto nessa fase escolar, como em outras etapas de ensino, lança-se mão de teorias psicológicas, pedagógicas e metodológicas a fim de possibilitar aos estudantes efetivas oportunidades de aprendizagem. Neste texto, procurou-se refletir acerca da articulação entre duas tendências metodológicas do campo da Educação Matemática: Etnomatemática e História da Matemática.

Diante disso, o objetivo que orientou o desenvolvimento do texto foi investigar quais os efeitos imediatos da articulação entre a História da Matemática e a Etnomatemática na realização de uma proposta de ensino, voltada à estudantes do $5^{\circ}$ ano do Ensino Fundamental. Para tal, elaborou-se uma proposta de ensino que apresentou aos estudantes do 50 ano três modos distintos para a realização do produto entre dois números. Em outras palavras, apresentou-se três formas de matematizar distintas da forma de matematizar da Matemática Escolar, realizadas com regras e jogos de linguagem específicos das formas de vida nas quais se desenvolveram. Os três modos de matematizar escolhidos foram encontrados na História da Matemática e são próprios de civilizações e povos com formas de vida bem características: hindu; chinesa; e, egípcia. 
Entre os efeitos imediatos observados, pode-se destacar que, por meio da proposta de ensino, os estudantes: sentiram-se motivados a aprender outras formas para a realização do produto; conheceram outros modos de matematizar; perceberam que os modos de matematizar ensinados por meio da Matemática Escolar não são o único meio para a realização do produto entre dois números; reforçaram sua aprendizagem sobre o algoritmo da multiplicação em seus jogos de linguagem escolares.

Em síntese, pode-se afirmar que as atividades realizadas ao longo da proposta de ensino possibilitaram aos estudantes: conhecer outras formas de matematizar, expressas em jogos de linguagens com suas regras específicas; rever aspectos relativos ao algoritmo da multiplicação convencional, presente nos jogos de linguagem da Matemática Escolar; refletir acerca das vantagens que outros jogos de linguagem têm sobre os jogos de linguagem da Matemática Escolar, e vice-versa.

Os efeitos observados possibilitam defender que um ensino mediado pela articulação entre a História da Matemática e a Etnomatemática contribui para a aprendizagem matemática dos estudantes, em particular, de 5o ano, ao mesmo tempo em que possibilita a esses mesmos estudantes ir além da Matemática. Isso, pois, a articulação proposta possibilitou expandir as discussões realizadas em sala para além da disciplina específica, integrando aspectos históricos e culturais, atribuindo mais valor e significado à aprendizagem matemática, mostrando o caráter humano da Matemática.

Por fim, vale ressaltar que outros efeitos poderiam ter sido observados caso um acompanhamento tivesse sido realizado junto aos estudantes, pois, desse modo, seria possível, por exemplo, verificar se de fato os estudantes utilizaram algum dos métodos abordados na proposta de ensino em sua prática diária. 


\title{
The multiplication algorithm: possibilities of different forms of mathematizing
}

\begin{abstract}
This article aims to investigate the immediate effects of the articulation between the History of Mathematics and Ethnomathematics in the realization of a teaching proposal, focused on at 5 th grade students. The proposal was made with eighteen students from a public school in the city of Porto Alegre, RS, and approached the teaching of multiplication. Data were obtained from a questionnaire with nine open-ended questions, applied to students after the proposal was made. In order to analyze the results, discursive genealogical analysis was used as method, using Michel Foucault's writings as analytical tools, in special on the concepts of power and knowledge, and Ludwig Wittgenstein, about language games and family similarities. It is evident that through the teaching proposal, the students: were motivated to learn other ways to produce the product; knew other ways to mathematize; reinforced their learning about the multiplication algorithm in their school language games. In addition, it is shown that the activities carried out throughout the teaching proposal allowed students to: know other forms of mathematization, through language games with their specific rules; review aspects related to the multiplication algorithm taught in schools; it also think about the advantages that other language games have over the School Math language game and conversely.
\end{abstract}

KEYWORDS: History of Mathematics. Ethnomathematics. Early Years. Elementary education. Multiplication. 


\section{NOTAS}

${ }^{1}$ Utiliza-se Matemática Acadêmica como a forma de matematizar resultante dos estudos e pesquisas realizadas por matemáticos da academia, nas universidades ou nos centros de pesquisa. Já por Matemática Escolar, entende-se a forma de matematizar praticada na escola, expressa nos livros didáticos com uma linguagem particular, mas diferente da linguagem da Matemática Acadêmica.

${ }^{2}$ A filosofia de Wittgenstein é dividida em dois momentos dissociáveis, sendo o primeiro marcado pela obra Tractatus Lógico-Philosophicus (1921) e o segundo pela obra Investigações Filosóficas (1953). Efeito disso, utilizam-se as expressões 'segundo Wittgenstein' ou 'filosofia de maturidade' para referenciar o segundo momento do pensamento do filósofo.

${ }^{3} E_{7}$ e $E_{11}$ não responderam a questão.

${ }^{4} E_{17}$ e $E_{18}$ não responderam esta e as demais questões analisadas.

\section{AGRADECIMENTOS}

Agradecemos à professora da turma por possibilitar a realização da proposta de ensino, bem como, à Coordenação de Aperfeiçoamento de Pessoal de Nível Superior - CAPES, pela bolsa de estudos concedida.

\section{REFERÊNCIAS}

BOYER, C. História da Matemática. Tradução Elza F. Gomide. São Paulo: Edgard Blucher LTDA, 1974.

D'AMBROSIO, U. Educação matemática: da teoria à prática. 4. ed. Campinas: Papiros, 1998.

D'AMBROSIO, U. A interface entre história e matemática: Uma visão históricopedagógica. In: John A. Fossa (Org.). Facetas do Diamante: ensaios sobre educação matemática e história da matemática. Rio Claro, SP: Editora da SBHMat, p. 241-271. 2000.

D'AMBROSIO, U. Etnomatemática - elo entre as tradições e a modernidade. 2. ed. 3a reimp. Belo Horizonte: Autêntica, 2007.

EVES, H. Introdução à História da Matemática. Tradução Hygino H. Domingues. Campinas: Editora da UNICAMP, 2004.

FOUCAULT, M. A arqueologia do saber. Tradução Luiz Felipe Baeta Neves. 3. ed. Rio de Janeiro: Forense Universitária, 1987.

FOUCAULT, M. Vigiar e punir: nascimento da prisão. Tradução de Raquel Ramalhete. 20. ed. Petrópolis: Vozes, 1999.

LARA, I. C. M. Histórias de um "lobo mau": a matemática no vestibular da UFRGS. 2001. 242 f. Dissertação (Mestrado em Educação) - Universidade Federal do Rio Grande do Sul, Porto Alegre, 2001. 
LARA, I. C. M. de. O ensino da matemática por meio da história da matemática: possíveis articulações com a etnomatemática. VIDYA, Santa Maria, v. 33, n. 2, p. 51-62, jul./dez., 2013.

MIGUEL, A. Três estudos sobre história e educação matemática. 1993. 274 f. Tese (Doutorado em Educação) - Universidade Estadual de Campinas, Campinas, 1993.

MIGUEL, A.; MIORIM, M. A. História na Educação Matemática: propostas e desafios. 2. ed. 1a reimp. Belo Horizonte: Autêntica Editora, 2017.

OMENA, B. S. S. de. A História da Matemática em propostas didáticas presentes em dissertações e teses brasileiras. 2015. 74 f. Dissertação (Mestrado Profissional em Ensino de Ciências) - Universidade Federal de Itajubá, Itajubá, 2015.

ROQUE, T. História da Matemática, uma visão crítica, desfazendo mitos e lendas. Rio de Janeiro: Zahar, 2012.

ROQUE, T. Desmascarando a equação. A história no ensino de que matemática? Revista Brasileira de História da Ciência, Rio de Janeiro, v. 7, n. 2, p. 167-185, jul./dez., 2014.

SANTOS, J. B. P. dos. et al. Etnomatemática e as práticas em sala de aula: um estudo apartir de dissertações e teses. In: CONGRESSO INTERNACIONAL DE ENSINO DAMATEMÁTICA, 7, 2017, Canoas. Anais do 70 Congresso Internacional de Ensino da Matemática. Canoas, 2017.

SILVA, E. S. da; TRIVIZOLI, L. T. Atividade sobre sistemas de numeração baseada em informações históricas: uma proposta de ensino para os anos iniciais do ensino fundamental. ACTIO, Curitiba, v. 3, n. 3, p. 336-357, set./dez. 2018. Disponível em: https://periodicos.utfpr.edu.br/actio/article/view/7704/5754 . Acesso em: 10 ago. 2019.

VEIGA-NETO, A. Foucault e a Educação. 3. ed. 1 reimp. Belo Horizonte: Autêntica, 2014.

VILELA, D. S. Etnomatemática e a virada linguística: práticas educacionais.

Boletim do LABEM. v. 7, n. 12, p. 45 - 59, jan./jul., 2016.

WITTGENSTEIN, L. Investigações Filosóficas. 2. ed. São Paulo: Abril Cultural, 1979. (Coleção Os Pensadores).

Recebido: 22 ago. 2019

Aprovado: 26 nov. 2019

DOI: $10.3895 /$ actio.v4n3.10589

Como citar:

SANTOS, J. B. P. dos; LARA, Isabel Cristina M. de. O algoritmo da multiplicação: possibilidades de diferentes formas de matematizar. ACTIO, Curitiba v. 4, n. 3, p. 629-651, set./dez. 2019. Disponível em:

https://periodicos.utfpr.edu.br/actio. Acesso em: XXX

Correspondência:

Juliana Batista Pereira dos Santos

Rua das Palmeiras, 272, apto 202. Cassino, Rio Grande, Rio Grande do Sul, Brasil.

Direito autoral: Este artigo está licenciado sob os termos da Licença Creative Commons-Atribuição 4.0

Internacional. 